\title{
Updated Role of Magnetic Resonance Imaging in Assessment of Endometriosis
}

\author{
SAFAA K. MOHAMED, M.D.; MARY Y. TADROS, M.D. and SHAYAN A. MOHAMED, M.Sc.
}

The Department of Radiodiagnosis and Nuclear Medicine, Faculty of Medicine, Ain Shams University

\begin{abstract}
Background: Endometriosis is a common disease, affecting $10 \%$ of all women of 'fertile' age. It is defined as the presence of ectopic endometrial glands and stroma outside the endometrium. It may vary from microscopic endometriotic implants to large cysts (endometriomas).

Aim of Study: The aim of this study is to evaluate the accuracy of the magnetic resonance imaging in diagnosis of endometriosis especially in non-apparent types as tubal and cul de sac endometriosis.

Patients and Methods: The studied group included 30 women in childbearing period, all of them referred from Obstetrics and Gynecology Department with clinical suspicion of endometriosis. They were sent to MRI unit at Ain Shams University Hospitals, for evaluation of the disease. The sensitivity, specificity and diagnostic accuracy for MRI were calculated.

Results: In our study 16 out of 30 cases were confirmed to have endometriosis by using MRI. MRI finding then compared with the results of laparoscope which with done after MRI in all patients to confirm diagnosis. Then we conclude that MRI showed a sensitivity of $93 \%$, specificity of $86 \%$ with overall accuracy rate of $90 \%$.

Conclusion: Magnetic resonance imaging (MRI) is a noninvasive, non-ionizing radiation method, offering high contrast resolution, which allows multiplanar evaluation of endometriosis, thus facilitating a preoperative diagnosis of the location and extent of endometriotic lesions.
\end{abstract}

Key Words: Endometriosis - Magnetic resonance imagingTransabdominal ultrasound.

\section{Introduction}

ENDOMETRIOSIS is benign gynecological condition that affects up to $10 \%$ of reproductive aged women [1].

There are three main distinct forms of pelvic endometriosis: Superficial (small deposits mainly

Correspondence to: Dr. Safaa K. Mohamed,

The Department of Radiodiagnosis and Nuclear Medicine, Faculty of Medicine, Ain Shams University recognized at laparoscopy), ovarian (endometriomas), and deep pelvic endometriosis (sub peritoneal invasion of endometrial tissue by at least $5 \mathrm{~mm}$ ) [2]

Deep infiltrating endometriosis can affect the retrocervical region, uterosacral ligament, rectum, rectovaginal septum, vagina, urinary tract and other extraperitoneal pelvic sites [3]

Dysmenorrhea, deep dyspareunia, dyschezia and dysuria are the most frequently reported symptoms but even psychological symptoms have been reported [4].

Laparoscopy defined as "gold standard" technique for diagnosis of endometriosis, but it is an invasive technique [ $\boldsymbol{s}$.

Ultrasound is a suitable screening and diagnostic modality for many processes because of its availability, lack of ionizing radiation, and low cost [6]

Transvaginal ultrasound (TVUS) or transabdominal ultrasound (TAUS), has a high sensitivity for adnexal lesions but a poor accuracy for other locations, especially for deep pelvic endometriosis, frequently giving false-negative results [7]

MRI is a non-invasive preoperative examination allow to identify all pelvic structures (with suband intraperitoneal location) with a high diagnostic accuracy that helps to identify endometriotic lesions to define the surgical strategy [8]

Recently, investigators have applied, diffusion weighted imaging (DWI), susceptibility weighted imaging (SWI), and dynamic contrast enhanced (DCE) MRI in order to improve the diagnostic performance of MRI in detecting atypical findings of endometriotic lesions and malignant transformation. 


\section{Patients and Methods}

\section{Patients:}

A retrospective study included 30 women in childbearing period. The patients age ranged from (22-48) years old (Table 1, Fig. 1), with the mean age of $35 \pm \mathrm{SD}$.

Table (1): Age distribution of the studied participants.

\begin{tabular}{lcc}
\hline Age categories & No. & $\%$ \\
\hline $22-30$ years & 11 & 36.7 \\
31-40 years & 11 & 36.7 \\
More than 40 years & 8 & 26.7 \\
\hline
\end{tabular}

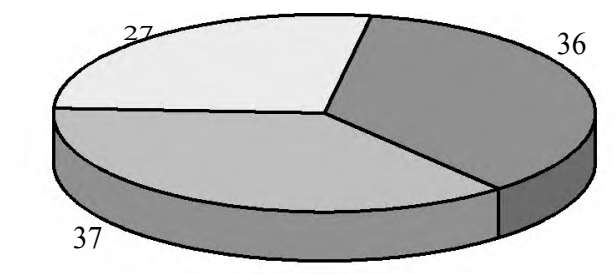

33.30 Years

31.40 Years $>40$ Years

Fig. (1): Age distribution of the studied participants.

All of patients referred from Obstetrics and Gynecology Department with clinical suspicion of endometriosis. They were sent to MRI unit at Ain Shams University Hospitals in Cairo during the period from May 2017 till December 2018.

Clinical presentations were as follows: 9 were represented with Abdominal pain, 3 were represented with dysmenorrhea, 3 was represented with dyspareunia, 2 with infertility, 2 were represented with menorrhagia 1 was represented cyclic painful anterior abdominal swelling, and 1 case of known endometriosis for pre-operative assessment (Table 2).

Inclusion criteria were females in reproductive age and patients with symptoms of dysmenorrhea, menorrhagia, pelvic pain, and infertility.

Exclusion criteria were Patients known to have contraindications for MRI, e.g. any metallic fragments or foreign bodies and Cardiac pacemaker.

Table (2): The number and percentage of different clinical presentation in childbearing period.

\begin{tabular}{lcc}
\hline Clinical presentation $(*)$ & Number & Percentage \\
\hline Abdominal pain & 9 & 60 \\
Dysmenorrhea & 3 & 20 \\
Dyspareunia & 3 & 20 \\
Infertility & 2 & 13.3 \\
Menorrhagia & 2 & 13.3 \\
Anterior abdominal swelling & 1 & 6.7 \\
Known endometriosis & 1 & 6.7 \\
\hline
\end{tabular}

(*) More than one Clinical presentation could be present in the same subject.
Prior to MRI imaging all patients will subjected to the following:

- Full history taking with a special emphasis on age, parity, age of menarche and pervious history of cesarean section.

-Vital sign monitoring: Including pulse and blood pressure measurement.

After MRI imaging all patients will subjected to the following:

- Laparoscope as gold standard method for diagnosis of endometriosis.

- Histopathological study after laparoscopic surgery to confirm our diagnosis.

\section{Acquisition and processing of MRI:}

A 1.5 T MR imaging unit (Philips, Healthcare) was used with a high resolution body coil and all of patients were imaged in the supine position.

Images obtained in at least 2 planes with T1and T2-weighted sequences. Addition of T2WISPIR as fat-suppression technique. Cuts were taken obliquely in orientation to the uterus. Parameters included were FOV 200-250mm, slice thickness $4 \mathrm{~mm}$, section gap $0.5-1 \mathrm{~mm}$, and matrix $192 \times 256$.

DWI and ADC maps were also done. Axial DWI with single shot echo planar imaging (EPI) performed at $b$-values of 0 and $800 \mathrm{~s} / \mathrm{mm}^{2}$. Contrast material was injected in 10 patient after checking renal functions (according to clinician's request), to exclude metastatic deposits and showed enhancement of solid lesion.

MRI analysis:

MR images analysis for following parameters:

Image analysis:

- Ovarian cystic lesions with high signal on T $1 \mathrm{WI}$ and shading on T2WI representing endometriomas.

- Dilated fallopian tubes with high signal intensity in T1WI, confirming hematosalpinx.

- Bloody foci seen as high signal lesions on fat suppressed images.

- Deep infiltrating lesions appear as hypointense masses with irregular, indistinct margins on T2weighted sequences.

- Diffusion restricted lesions on DWI and ADC map to detect deep infiltrating lesions not detected on conventional sequences.

Statistical analysis:

The collected was revised, coded, tabulated and introduced to a PC using statistical package for social sciences (IBM SPSS 20.0). To determine 
the diagnostic value of MRI, data was presented and suitable analysis was done according to the type of data obtained for each parameter. The following measures were then calculated: Sensitivity, specificity, and overall diagnostic accuracy.

\section{Results}

Our study included (30) female patients in child bearing period with clinical suspicion of endometriosis. 16 out of 30 cases were confirmed to have endometriosis by using MRI.

The patients age ranged from (22-48) years old (Table 1, Fig. 1). Most of the patients presented by dysmenorrhea, menorrhagia, pelvic pain, and infertility.

By MRI, 2 out of 2 cases were confirmed to have bilateral ovarian endometriomas. Unilateral ovarian endometriomas were also confirmed by MRI in 5 cases (Fig. 2), 4 cases were confirmed to have unilateral adenexal endometriomas. MRI also confirmed 1 case of hematosalpinx, 7 cases of adenomyosis (Fig. 3), 5 ill-defined lesions, 2 of them related to surgical scar (Fig. 4), and 3 cases DIEs (Fig. 5). MRI also showed 2 cases of simple ovarian cysts and 1 case showed hemorrhagic cyst.



Fig. (2): A 29 years old female patient presented with deep seated pelvic pain. (a) Axial T 1 WI, (b) coronal T2WI and (c) SWI, show large right ovarian cystic lesion with different ages of blood inside, recent blood eliciting low signal (white arrow) in SWI (c), with subacute blood eliciting high signal (star) in T1 (a), T2 (b), and in SWI (c). Relatively old blood with T2 shading eliciting high signal in T1 and SWI (red arrows). This large right cystic endometriotic lesion is seen resting on the posterior aspect of the uterus (b).

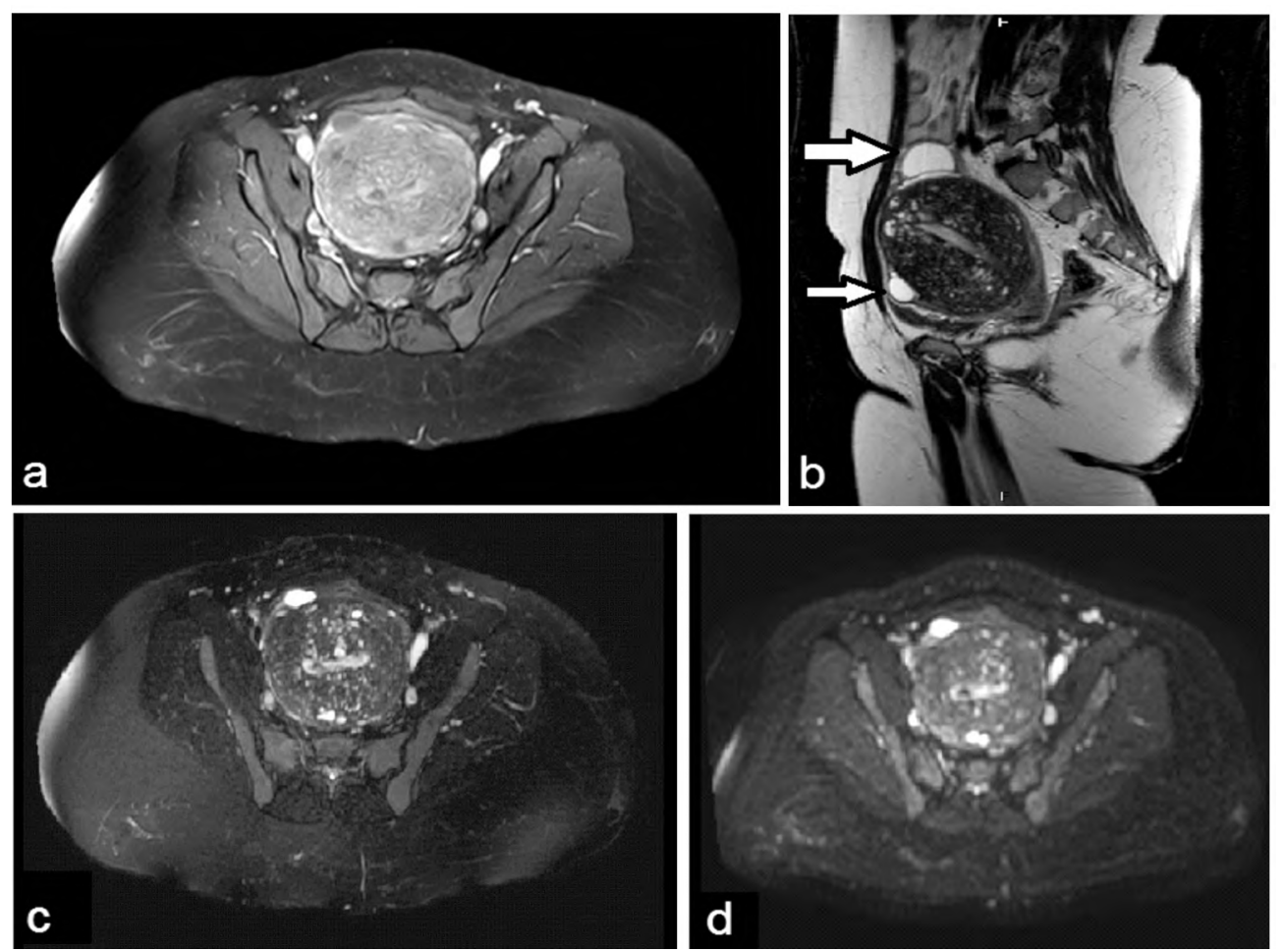

Fig. (3): A 29 years old female patient complaining of menometrorrhagia and primary infertility. (a) Axial T1 WI, (b) sagittal T2WI, (c) axial T2WI SPIR and (d) DWI, in these images the uterus is seen bulky with arcuate shape. The myometrium is seen diffusely thickened with hypointense signal on T1 (a) and T2 (b), it shows innumerable tiny cystic foci embedded within of high signal on T2 (b) denoting cystic changes, picture is suggestive of diffuse form of adenomyosis with subsequent distorted uterine cavity. Note preserved signal in fat suppressed image (c) and restricted diffusion in DWI (d). 

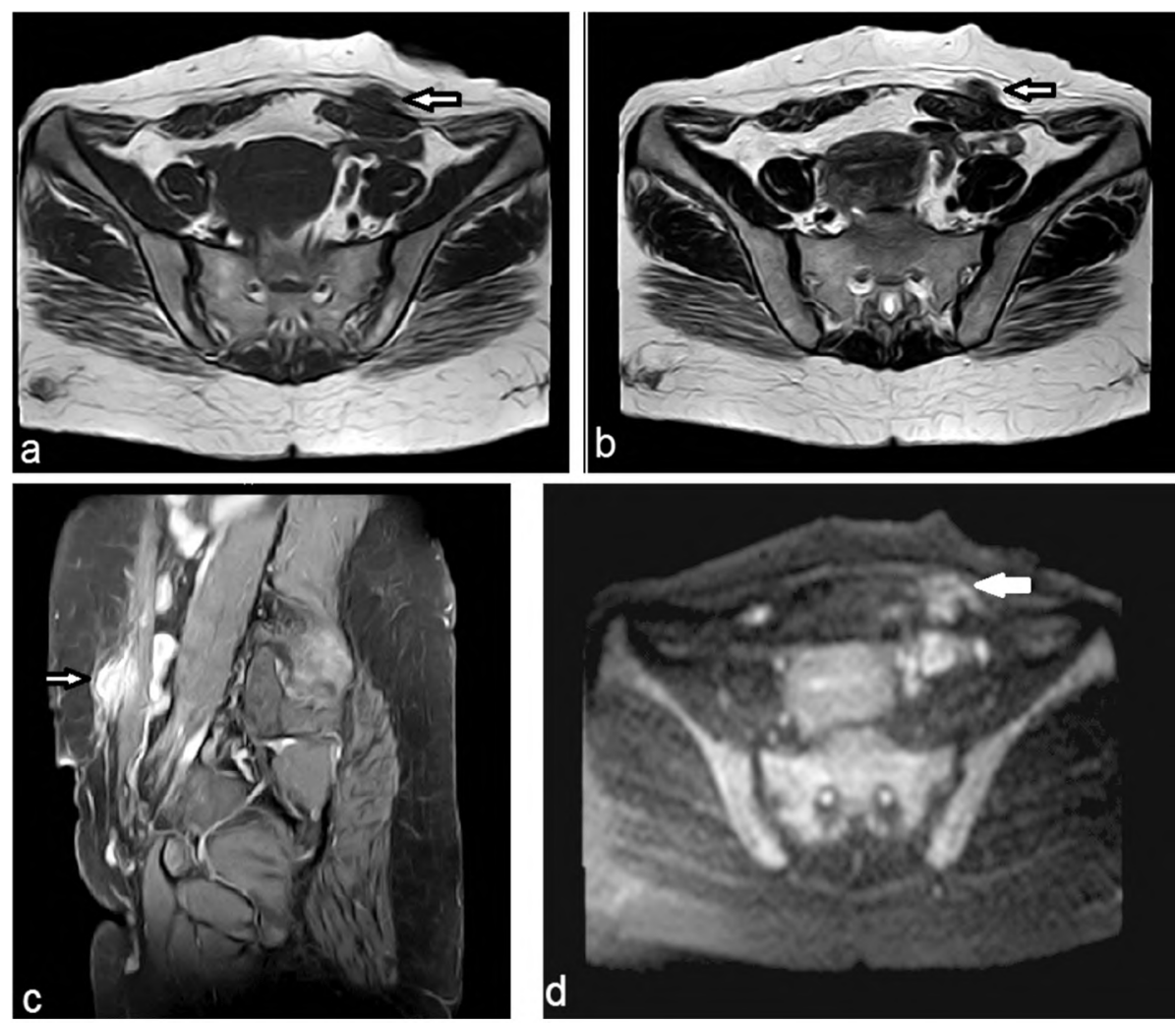

Fig. (4): A 38 years old female presented with anterior abdominal wall swelling with cyclic pain. (a) Axial T1W, (b) axial T2W, (c) sagittal T1W post contrast and (d) axial DWI, show a poorly marginated anterior pelvic wall lesion (arrow) displaying low signal intensity in T1(a), heterogenous low and isointense signal in T2 (b), enhancement in post contrast study (c) and restricted diffusion in DWI (d). The lesion is seen overlying and partially non-separable from the left rectus abdominis, feature suggesting abdominal wall endometriosis.
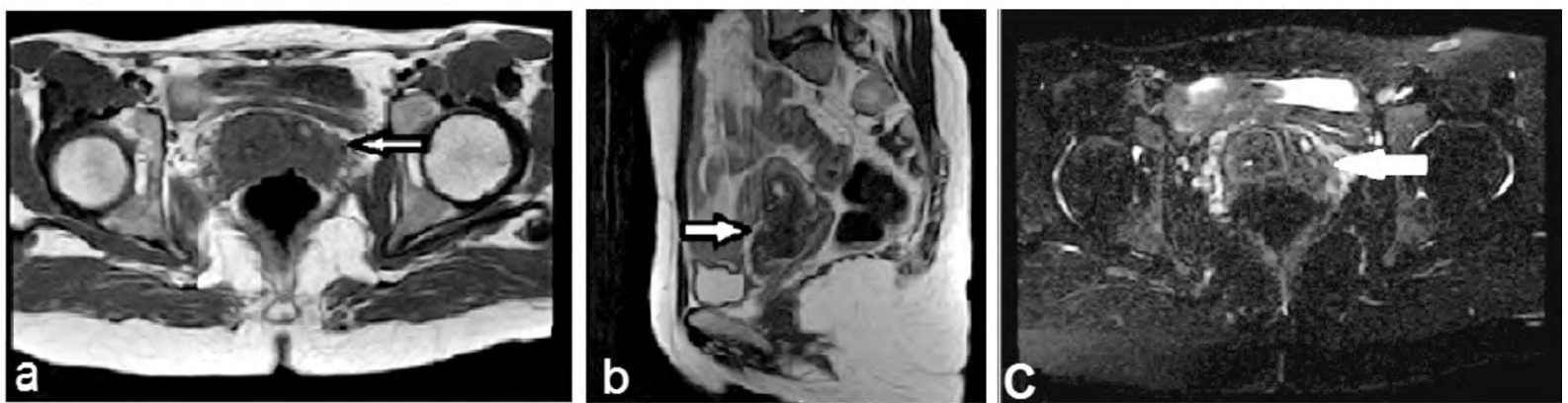

Fig. (5): A 33 years old female patient complaining of dyspareunia. (a) Axial T1WI, (b) sagittal T2WI and (c) axial T2WI SPIR, show irregular solid mass (arrow), seen at the vesiccovaginal septum on the left side as well as anterior vaginal wall and anterior uterine wall (b). The mass is hypointense on T2 (b), intermediate on T1 (a) with hyperintense focus, this focus is still hyperintense on fat suppressed images (c). Obliteration of rectovaginal pouch is also noticed these features mostly represent endometriotic implant at the vesicovaginal septum, anterior uterine and vaginal walls.

By using laparoscopy followed by histopathological study which is the gold standard method for diagnosis of endometriosis, 7 cases confirmed to have adenomyosis, 2 cases of abdominal wall endometriosis which related to surgical scar implants, 5 cases showed endometriotic implants in various pelvic positions (DIE). 6 cases turned to have unilateral ovarian endometriomas, 2 out of 2 were confirmed to have bilateral ovarian endome- triomas. Confirmation of the diagnosis was also done in 2 out of 4 cases of unilateral adenexal endometriomas, as 2 cases were misdiagnosed by MRI giving false positive results. Laparoscope also confirmed 1 cases of hematosalpinx. MRI finding then compared with the results of laparoscope which was done after MRI in all patients to confirm diagnosis. The correlation of MRI results with Laparoscopic results are listed in (Table 3). 
Table (3): Correlation of MRI results with laparoscopic results.

\begin{tabular}{lcc}
\hline Findings & MRI & $\begin{array}{c}\text { Positive } \\
\text { laparoscopic } \\
\text { results }\end{array}$ \\
\hline Adenomyosis & 7 & 7 \\
Unilateral ovarian endometriomas & 5 & 6 \\
Ill-defined lesions (superficial and DIE) & 5 & 7 \\
Unilateral adenexal endometriomas & 4 & 2 \\
Bilateral ovarian endometriomas & 2 & 2 \\
Simple ovarian cysts & 2 & 0 \\
Hematosalpinx & 1 & 1 \\
\hline
\end{tabular}

Total findings exceeded the number of patients and more than one patient had double pathology picture.

By that we conclude that MRI showed a sensitivity of $93 \%$, specificity of $86 \%$ with overall accuracy rate of $90 \%$.

\section{Discussion}

Endometriosis is the presence of estrogen dependent endometrial tissue outside the uterus and is a common benign gynecologic condition that affects up to $10 \%$ of reproductive aged women [1]

In our study, 30 patients suspected to have endometriosis were presented with different symptoms. Our aim was to evaluate the accuracy of MRI in diagnosis of endometriosis, detect deep infiltrating lesions and define the extent of the disease.

Ultrasound (US) is usually performed first and most commonly used imaging technique for the evaluation of patients with pelvic symptoms and infertility. A transabdominal and a transvaginal approach must be used systematically whenever possible [9].

The current research was a retrospective study to determine the need of MR imaging in radiological diagnosis of endometriosis. MRI showed a sensitivity of $93 \%$, specificity of $86 \%$ with overall accuracy rate of $90 \%$.

A study done in 2015 had stated that MRI is the most specific modality for diagnosis of endometriosis, with a sensitivity of $90 \%$ and a specificity of $98.6 \%$ [10].

Other comparable one had confirmed that MRI had a reported sensitivity and specificity value ranging from $69-92 \%$ and $75-98 \%$ respectively [11].
Another study done in 2018 concluded that MRI showed a sensitivity of $90.3 \%$ and a specificity of $91 \%$ [12]

In our study, 9 cases were suspected to have endometriotic cysts by clinical presentations and sonography and referred to MRI unit to confirm diagnosis.

MRI confirmed the sonographic findings of 9 cases of endometriomas, however on laparoscopy 1 case of ovarian endometriotic cyst was discovered that was misdiagnosed as hemorrhagic cyst by MRI.

Also, two cases of ovarian tumors with internal haemorrhage were discovered on laparoscopy that were misdiagnosed as ovarian endometriotic cyst by MRI giving false positive results.

By conventional MRI endometriomas showed high signal on T1 weighted images with shading on T2 weighted images. 4 cases showed bilaterality and multifocal adnexal lesions. All cases of endometrioma showed preserved hyperintensity on fat suppressed images and diffusion restriction in DWI. This was in agreement with Hoyos et al., who said that endometrioma typically will appear as cystic masses with relatively homogeneous hyperintensity on T1-weighted images and variable hypointensity on $\mathrm{T} 2$-weighted images (T2 shading). In the presence of an adnexal lesion with highintensity on T1-weighted images, besides endometriomas, the differential would include hemorrhagic cysts (which are often unilateral and resolve with time) and dermoid ovarian cysts (which show loss of T1-hyperintensity on fat suppressed images)

And in agreement with Duarte et al., who said that on DWI, endometriomas can exhibit high SI on DWI (restricted diffusion) due to their thick proteinaceous and hemoglobin degradation products

We applied susceptibility-weighted MR technique (SWI) in one case (Fig. 1) of endometrioma that showed large cystic lesion with different ages of blood inside, recent blood eliciting low signal, with subacute eliciting high signal, and relatively old blood eliciting relative high signal in SWI. This was in agreement with Takeuchi et al., who said that an additional of SWI to conventional MRI which is sensitive to hemorrhage in different phases could improve the diagnostic ability of endometrioma [15] 
Adenomyosis of the uterus represents heterotopic endometrial glands and stroma in the myometrium with adjacent smooth muscle hypertrophy [10].

In our study, 7 cases were confirmed to have adenomyosis by MRI, 3 cases were missed in the referred sonography.

Our MR findings of adenomyosis include poorly defined junctional zone margins, intrazonal T2hyperintense punctate foci representing cystic dilatation of heterotopic gland and $\mathrm{T} 1$-hyperintense punctuate foci indicating hemorrhage, all of which are findings that add specificity to the diagnosis this was in agreement with Shwayder and Sakhel, who said that features of adenomyosis on MRI include low-signal-intensity widening of the junctional zone on T2-weighted images, as well as scattered foci of increased signal intensity throughout the myometrium [16]

Laparoscopic results were the same as MRI, giving 100\% specificity for MRI in cases of adenomyosis.

Extra pelvic endometriosis can occur in any location in the body but most frequently occurs along the abdominal wall [12] .

In our study 2 cases were suspected to have abdominal wall endometriosis (AWE) by transabdominal ultrasound and referred to us to confirm diagnosis by MRI.

MRI confirmed the sonographic diagnosis of AWE, the lesion appeared at MRI as poorly marginated anterior pelvic wall lesion displaying a low signal on T 1 WI, heterogenous low and isointense T2 signal with inhomogeneous post contrast enhancement and diffusion restriction in DWI.

This was in agreement with Menni et al., who said that extra-genital endometriosis at MRI shows as solid masses or soft tissue thickening, with low to intermediate signal in both T2 and T1 weighted images (like most fibrotic lesions); the margins are usually irregular or stellate [17].

According to Fernández and Ortega, the presence of T1-weighted hyperintensity within a dilated serpiginous fallopian tube is pathognomonic finding of endometriosis [18].

One case was suspected to have hematosalpinx on ultrasound and confirmed on MRI. Laparoscopic results were the same as MRI, giving 100\% specificity for MRI in cases of hematosalpinx.
Deep pelvic endometriosis, or deep infiltrating endometriosis, is defined as deep endometriotic lesions penetrating under the surface of the peritoneum or the wall of the pelvic organs to a depth that exceeds $5 \mathrm{~mm}$ [12].

MRI is superior to ultrasound in detecting DIE. 1 case was suspected by ultrasound. On conventional MRI, 3 cases were detected. Later on, laparoscopy two endometriotic lesions appeared as very small areas of tissue distortion that was missed by MRI giving false negative results.

By MRI 3 cases turned to have endometriotic implants in vasicovaginal septum, Douglas pouch and left ovary. They appeared as irregular solid mass or nodule showed hypointense signal on T2WI and intermediate signal on T1WI with hypointense foci, these foci are still hyperintense on fat suppressed images denoting bloody or proteinaceous content. This was in agreement with TranHarding et al., who said that MRI characteristics of deep pelvic endometriosis vary depending on lesion type. Deeply infiltrating endometriotic implants may appear as punctate foci of hyperintense signal on T1WI. Solid deep lesions can demonstrate uniformly low signal intensity on T2WI with punctate areas of high signal on T 1 WI corresponding to regions of hemorrhage [12].

\section{Conclusion:}

MRI has a better specificity in the detection of the endometriotic lesion, especially with the use of additional DWI and SWI yields better diagnostic accuracy with better detection and evaluation of the extent of DIE and in confirming the diagnosis.

\section{References}

1- CLAIR K., WOLFORD J., VERAN-TAGUIBAO S., KIM G. and ESKANDER R.N.: Primary low-grade endometrial stromal sarcoma of the omentum. Gynecologic Oncology Reports, 21: 119, 2017.

2- DE VENECIA C. and ASCHER S.M.: "Pelvic endometriosis: Spectrum of magnetic resonance imaging findings". Seminars in Ultrasound, CT and MRI. WB Saunders, 36 : 385-393, 2015.

3- PONTIS A., ARENA I. and ANGIONI S.: "Umbilical endometriosis primary site without pelvic endometriosis and previous surgery: A case report. "Giornale Italiano di Ostetricia e Ginecologia, 36: 336-8, 2014.

4- MELIS I., AGUS M., PLUCHINO N., DI SPIEZIO SARDO A., LITTA P., MELIS G.B. and ANGIONI S.: Alexithymia in women with deep endometriosis? A pilot study. J. Endometriosis. Pelvic Pain Dis., 6: 26-33, 2014.

5- BENAVENT R.M.V.: "MRI findings in endometriosis". European Congress of Radiology, 1364, 2015.

6- YOUNG S.W., SAPHIER N.B., DAHIYA N., MENIAS C.O., BRIDGE A.A., CZAPLICKI C.D. and PATEL 
M.D.: Sonographic evaluation of deep endometriosis: Protocol for a US radiology practice. Abdominal Radiology, 41: 2364-2379, 2016.

7- MAUTONE S. SIMONA MAUTONE, SALVATORE BELLUARDO, VALERIO DI PAOLA, LUIGI ROMANO, GIOVANNI FOTI, RICCARDO MANFREDI, and ROBERTO POZZI MUCELLI: MRI of the Female and Male Pelvis, 69, 2014.

8- PUCHKOVA E.: "Role of MRI in detection of deep infiltrating endometriosis". European Congress of Radiology, 1-26, 2015.

9- BUY J.N. and GHOSSAIN M.: "Secondary Mullerian System." Gynecological Imaging. Springer Berlin Heidelberg, 439-505, 2013.

10- MANOUKIAN S.B., SHAHEEN N.H. and KOWAL D.J. Gynecologic Adenomyosis and Endometriosis: Key Imaging Findings, Mimics, and Complications. Contemporary Diagnostic Radiology, 38.7: 1-6, 2015.

11- BOURGIOTI C., PREZA O., PANOURGIAS E., CHATOUPIS K., ANTONIOU A., NIKOLAIDOU M.E. and MOULOPOULOS L.A.: MR imaging of endometriosis: Spectrum of disease. Diagnostic and Interventional Imaging, 98.11: 751-767, 2017.

12- TRAN-HARDING K., NAIR R. T., DAWKINS A.,
AYOOB A., OWEN J., DERANEY S. and GANESH H.: Endometriosis revisited: AN imaging review of the usual and unusual manifestations with pathological correlation. Clinical Imaging, 52: 163-171, 2018.

13- HOYOS L.R., JOHNSON S. and PUSCHECK E.: Endometriosis and imaging. Clinical Obstetrics and Gynecology, 60.3: 503-516, 2017.

14- DUARTE A.L., DIAS J.L. and CUNHA T.M.: Pitfalls of diffusion-weighted imaging of the female pelvis. Radiologia Brasileira, 51.1: 37-44, 2018.

15- TAKEUCHI M., MATSUZAKI K. and HARADA M.: Susceptibility-weighted MRI of extra-ovarian endometriosis: preliminary results. Abdominal Imaging, 40.7: 2512 2516, 2015.

16- SHWAYDER J. and SAKHEL K.: "Imaging for uterine myomas and adenomyosis". Journal of Minimally Invasive Gynecology, 21.3 : 362-376, 2014.

17- MENNI K., FACCHETTI L. and CABASSA P.: Extragenital endometriosis: Assessment with MR imaging. A pictorial review. The British Journal of Radiology, 89.1060: 1-23, 2016.

18- FERNÁNDEZ R.M. and ORTEGA J.B.: "Magnetic resonance imaging of pelvic endometriosis". Radiología (English Edition), 59.4: 286-296, 2017.

\section{تحلديث دور التصوير بالرنين المغناطيسى فى تقييم مرض إنرة بطانة الرحم المهاجرة}

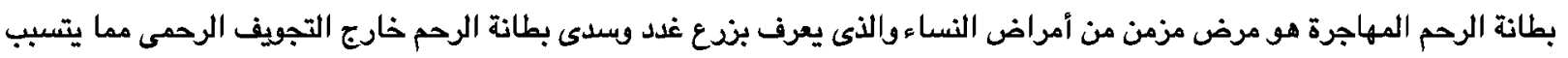
في آلام الصوض والعقم.

العلاج الأساسى لأمتداد بطانة الرحم المهاجرة هو الإظستئصسال الجراحى الكامل لذلك التقييم الدقيقلأمتداد بطانة الرحم قبل التدخل



يستخدم التصوير بالرنين المغناطيسى للصوض على نطاق واسع فى تقييم مرض بطانة الرحم المهاجرة والتصوير الأولى المرض يكون بالموجات الصوتية.

تصوير الحوض بالرنين المغناطيسى هو طريقة غير جائرة عالية التباين والتى تسمح بتقييم متعدد الأسطح مع توصيف جير للأنسجة،



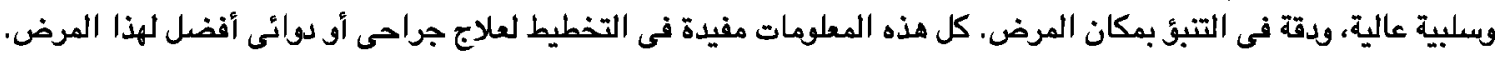

في الآتئة الأخيرة التشخيصيين طبقوا التصوير ذو الثقل بالإنتشار DWI والتصوير ذو الثقل بالقابلية SWI وتعزيز التباين الديناميكى

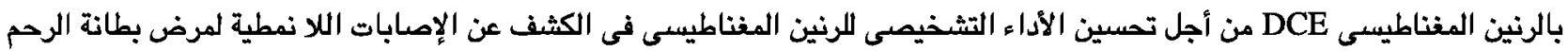



وعلى الرغم من أن كل هذه الطرق الحديثة أضافت إلى التصوير التقليدى اللرنين المغناطيسى وأظهرت نتائج أولية واعدة، لكنها لا تزال

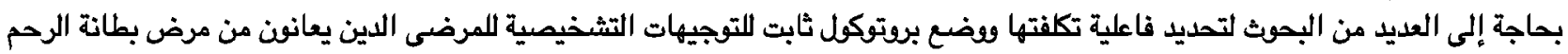

